\title{
For Rosie
}


John Narayan - 9781526101020

Downloaded from manchesterhive.com at $04 / 26 / 2023$ 09:36:13AM 